\title{
Chronic Inactivation of a Neural Circuit Enhances LTP by Inducing Silent Synapse Formation
}

\author{
Kristin L. Arendt, ${ }^{1}$ Federica Sarti, ${ }^{1,2}$ and Lu Chen ${ }^{1}$ \\ ${ }^{1}$ Department of Psychiatry and Behavioral Sciences and Stanford Institute of Neuro-Innovation and Translational Neuroscience, Stanford University School \\ of Medicine, Stanford, California 94305-5453, and ${ }^{2}$ University of California, Department of Molecular and Cell Biology, Berkeley, California 94720-3200
}

Chronic inactivation of a neural network is known to induce homeostatic upregulation of synaptic strength, a form of synaptic plasticity that differs from Hebbian-type synaptic plasticity in that it is not input-specific, but involves all synapses of an individual neuron. However, it is unclear how homeostatic and Hebbian synaptic plasticity interact in the same neuron. Here we show that long-term potentiation (LTP) at Schaffer collateral-CA1 synapses is greatly enhanced in cultured mouse hippocampal slices after chronic (60 h) network-activity blockade with tetrodotoxin (TTX). This increase in LTP is not due to an altered synaptic NMDA receptor composition or presynaptic function. Instead, we found that silencing neural network activity not only increases the abundance of both AMPA and NMDA receptors at existing synapses as previously described, but also promotes the presence of new glutamatergic synapses that contain only NMDA receptors - a class of synapses that are functionally silent due to the absence of AMPA receptors. Induction of LTP in TTX-treated neurons leads to insertion of AMPA receptors into the silent synapses, thereby "switching on" these silent synapses, which produces the observed enhancement of LTP magnitude. Our findings suggest that homeostatic synaptic plasticity manifests not only in the adjustment of the strength of existing synapses, but also in the modulation of new synapse formation/maintenance. Moreover, presence of new but functionally silent synapses enables more robust LTP to occur through rapid conversion of silent synapses to active synapses, resulting in a stronger input-specific modulation of synapses following prolonged network silencing.

\section{Introduction}

One of the defining features of the nervous system is its ability to modify synaptic strength in an experience-dependent manner. These changes in synaptic strength, also called synaptic plasticity, can be short- or long-lasting. Long-term plasticity can be divided into two main categories: Hebbian-type and homeostatic. Hebbian plasticity emphasizes adjusting the relative strength between different synapses through strengthening (or weakening) of a subset of activated synapses in an input-specific fashion, thereby allowing the network to learn to generate optimal outputs in response to specific inputs. Homeostatic plasticity, however, adjusts synaptic strength globally in a multiplicative fashion so as to preserve the stability of the network while maintaining the relative synaptic weights of the overall circuit; therefore, it is also referred to as synaptic scaling (Turrigiano and Nelson, 2004; Davis, 2006). Although operating under different computational rules and likely involving distinct molecular mechanisms, these two types of synaptic plasticity may partly share cellular signaling pathways and converge at the point of final common effectors at

\footnotetext{
Received Aug. 14, 2012; revised Nov. 25, 2012; accepted Dec. 5, 2012.

Author contributions: K.L.A. and L.C. designed research; K.L.A., F.S., and L.C. performed research; K.L.A., F.S., and L.C. analyzed data; L.C. wrote the paper.

The research was supported by the David and Lucile Packard Foundation, the W. M. Keck Foundation, and National Institute of Mental Health Grants 1P50MH86403 and 1R01MH091193 (to L.C.). We thank Christine Plant for critical comments on the manuscript.

Correspondence should be addressed to Lu Chen, 265 Campus Drive, Room G1034B, Lorry I. Lokey Stem Cell Research Building, Stanford University, Stanford, CA 94305-5453. E-mail: luchen1@stanford.edu.

DOI:10.1523/JNEUROSCI.3880-12.2013

Copyright $\odot 2013$ the authors $\quad 0270-6474 / 13 / 332087-10 \$ 15.00 / 0$
}

the synapse- the presynaptic release machinery and postsynaptic receptors (Thiagarajan et al., 2007; Pozo and Goda, 2010). Therefore, it is conceivable that homeostatic synaptic plasticity may act as a form of metaplasticity to influence the subsequent induction of Hebbian plasticity.

Previous work has shown that chronic silencing of network activity with TTX leads to increased synaptic strength (Turrigiano et al., 1998; Sutton et al., 2006; Soden and Chen, 2010; Wang et al., 2011), which is achieved by an increase in postsynaptic glutamate receptor abundance. In the CNS, two major ionotropic glutamate receptors-AMPA- and NMDA-type receptors (AMPARs and NMDARs, respectively) — mediate synaptic transmission and synaptic plasticity. In the case of TTX blockade, both AMPAR- and NMDAR-mediated synaptic responses go up (Watt et al., 2000), suggesting synaptic insertion of both AMPARs and NMDARs as a result of homeostatic synaptic plasticity. Since some forms of Hebbian plasticity are also expressed postsynaptically through modulation of receptor abundance in the synaptic membrane (Nicoll and Malenka, 1999), it is possible that the upregulation of AMPARs at recently scaled synapses may cause diminished LTP because there is likely limited capacity for AMPAR insertion.

To directly examine the impact of network silencing and homeostatic synaptic plasticity on subsequent induction of Hebbian plasticity, we investigated NMDAR-dependent LTP at Schaffer collateral-CA1 synapses in cultured hippocampal slices after chronic TTX treatment that caused synaptic upscaling of both the AMPARs and NMDARs. Surprisingly, we found a striking increase in LTP magnitude in TTX-treated slices. The en- 
hanced LTP is not due to changes in NMDAR subunit composition (e.g., NR2A- vs NR2B-containing NMDARs). Instead, we found that chronic activity blockade leads to more new synapses that contained only NMDARs but not AMPARs, and therefore are functionally silent. Moreover, we provide evidence that LTP induction activates these silent synapses by inducing AMPAR insertion into the postsynaptic density, thereby producing greater LTP. Thus, homeostatic synaptic plasticity can have a direct impact on Hebbian synaptic plasticity by both modifying existing synapses and by promoting or triggering synaptogenesis.

\section{Materials and Methods}

Slice culture. Organotypic slice cultures were prepared from young C57BL/6 mouse pups of either sex (postnatal day 6-7) and placed on semiporous membranes (Millipore) for 5-7 d before recording (Gähwiler et al., 1997). Briefly, slices were maintained in an MEM-based culture media comprised of $1 \mathrm{mM} \mathrm{CaCl}_{2}, 2 \mathrm{mM} \mathrm{MgSO}_{4}, 1 \mathrm{~mm} \mathrm{L-glutamine,} 1$ $\mathrm{mg} / \mathrm{L}$ insulin, $0.0012 \%$ ascorbic acid, $30 \mathrm{~mm}$ HEPES, $13 \mathrm{~mm}$ D-glucose, and $5.2 \mathrm{~mm} \mathrm{NaHCO}_{3}$ (pH, 7.25; osmolarity, $320 \mathrm{mOsm}$ ).

Cultures were maintained in an incubator with $95 \% \mathrm{O}_{2} / 5 \% \mathrm{CO}_{2}$ at $34^{\circ} \mathrm{C}$.

Electrophysiology. Voltage-clamp whole-cell recordings were obtained from CA1 pyramidal neurons treated with either vehicle controls or $1 \mu \mathrm{M}$ TTX for $60 \mathrm{~h}$ before recording under visual guidance using transmitted light illumination. Control and TTX cells were obtained from the same batches of slices on the same experimental day. The recording chamber was perfused with $119 \mathrm{~mm} \mathrm{NaCl}, 2.5 \mathrm{~mm} \mathrm{KCl}, 4 \mathrm{~mm} \mathrm{CaCl} 2,4 \mathrm{~mm} \mathrm{MgCl} 2$, $26 \mathrm{~mm} \mathrm{NaHCO} 3,1 \mathrm{~mm} \mathrm{NaH} \mathrm{PO}_{4}, 11 \mathrm{~mm}$ glucose, $0.1 \mathrm{~mm}$ picrotoxin, and $4 \mu \mathrm{M}$ 2-chloroadenosine, at $\mathrm{pH} 7.4$, gassed with $5 \% \mathrm{CO}_{2} / 95 \% \mathrm{O}_{2}$, and held at $30^{\circ} \mathrm{C}$. Patch recording pipettes $(4-6 \mathrm{M} \Omega$ ) were filled with 115 mM cesium methanesulfonate, $20 \mathrm{~mm} \mathrm{CsCl}, 10 \mathrm{~mm}$ HEPES, $2.5 \mathrm{~mm}$ $\mathrm{MgCl}$, 4 mm Na2ATP, $0.4 \mathrm{~mm}$ Na3GTP, $10 \mathrm{~mm}$ sodium phosphocreatine, and $0.6 \mathrm{~mm}$ EGTA at pH 7.25.

Spontaneous miniature transmission was monitored in the presence of $1 \mu \mathrm{M}$ TTX. Synaptic responses were evoked with bipolar electrodes using single-voltage pulses ( $200 \mu \mathrm{s}$, up to $20 \mathrm{~V}$ or $10 \mathrm{~mA}$ ). The stimulating electrodes were placed over Schaffer collateral fibers between 300 and $500 \mu \mathrm{m}$ from the recorded cells. All evoked synaptic responses were obtained following a washout of the TTX treatment. Synaptic AMPARmediated responses were measured at $-60 \mathrm{mV}$ and NMDAR-mediated responses at $+40 \mathrm{mV}$, at a latency where AMPAR responses had fully decayed $(60 \mathrm{~ms})$. Synaptic responses were averaged over 50-100 trials. For the ifenprodil sensitivity assay, baseline-evoked responses were obtained in whole-cell configuration with a holding potential of $-60 \mathrm{mV}$ in the presence of ACSF containing $10 \mu \mathrm{M}$ CNQX and lacking $\mathrm{Mg}^{2+}$. Ifenprodil ( $3 \mu \mathrm{M}$; Tocris Bioscience) was washed on and recordings from the same cell were obtained in the presence of $3 \mu \mathrm{M}$ ifenprodil after $30 \mathrm{~min}$ of exposure. Stimulation ( 50 pulses at $0.3 \mathrm{~Hz}$ ) $15 \mathrm{~min}$ after washing on ifenprodil was performed to ensure blockade of the NR2B subunit due to its use-dependent blockade nature. Data from $30 \mathrm{~min}$ of exposure to ifenprodil is presented in this study. Failure rate experiments were performed using minimum stimulation. Failure rate was calculated as a percentage of failed evoked responses over 50 sweeps at a holding potential of -60 and $+40 \mathrm{mV}$. We used the peak amplitudes of individual responses as the criterion for defining success or failure. The peak amplitudes of each response were measured objectively using an automated macro in ClampFit (Axon). We them used a threshold (10 pA for responses at $-60 \mathrm{mV}$ and $20 \mathrm{pA}$ for responses at $+40 \mathrm{mV}$, measured from noise envelop) as a cutoff criterion-responses with a peak amplitude above the threshold were counted as success. The success trials had a clear response above the baseline and displayed kinetics in line with evoked NMDAR responses. In amplitude scatter plots, for ease of visualization, we defined the amplitudes of failure trails as zero. Field EPSPs (fEPSPs) were acquired with $2.5 \mathrm{M} \mathrm{NaCl}$ in the recording pipette.

LTP was induced using a pairing protocol stimulating Schaffer collateral fibers at $3 \mathrm{~Hz}$ ( 540 pulses) while depolarizing the postsynaptic cell to $0 \mathrm{mV}$. For slices exposed to TTX for scaling, TTX was washed out before whole-cell patch-clamping. For LTP experiments where NMDAR block- ade was necessary, slices were exposed to $100 \mu \mathrm{M}$ APV or $3 \mu \mathrm{M}$ ifenprodil at least $25 \mathrm{~min}$ before whole-cell patch. Failure rate and mEPSC frequency assays following LTP were performed 50-60 min postinduction, when LTP levels were established and maintained. All electrophysiological recordings were performed with Multiclamp 700B amplifiers (Molecular Devices), analysis was complete in ClampFit, MiniAnalysis (Synaptosoft), Excel (Microsoft), and Prism (GraphPad).

Image acquisition and analysis. Before imaging, dissociated cells were transfected with GFP via Lipofectamine. Following methanol/PFA fixation, control and TTX-treated cells were triple-stained for GFP (Cy2chicken), VGlut1 (Cy5-Guinea Pig), and either NR1 (Cy3-mouse) or GluR1 (Cy3-mouse). Cells were then mounted using Fluromount G. For fluorescent image analysis, cells were chosen randomly from three or more coverslips per group. Fluorescent images were acquired with an Olympus FV1000 BX61WI laser-scanning confocal microscope, using an Olympus Plan Apochromat $60 \times$ oil objective [numerical aperture (NA), 1.42; working distance (WD), 0.15] or an Olympus U-Plan Apochromat $100 \times$ oil objective (NA, 1.40; WD, 0.12 ) with sequential acquisition setting at $1024 \times 1024$ pixel resolutions. Laser power and photomultipliers were set such that no detectable bleed through occurred between different channels. Digital images of the cells were captured with Fluoview Imaging software (Olympus). For each image, $8-10$ sections were taken, and brightest point projections were made. Identical settings for laser power, photomultiplier gain, and offset were used in each experiment. Pixel intensities for the brightest samples were just below saturation, except when contours of the cell or of the neuronal processes had to be clearly determined (e.g., saturated pixels at the soma of neurons to detect dendritic signals). For the analysis of synaptic proteins, images from the same experiment were thresholded identically by intensity to exclude the diffuse/intracellular pool. Synaptic colocalization was defined as a minimum two-pixel overlap between the VGluT1 signal and the NR1 or GluR1 signal. To reduce the effect of background staining on synaptic colocalization analysis, VGluT1 puncta smaller than $0.4 \mu \mathrm{m}^{2}$ were excluded from analysis. Image quantification was performed blind to treatment group using MatLab.

Statistical analysis. All graphs represent average values \pm SEM. For each experimental group, the $N$ and $n$ numbers represent the number of independent experiments and the total number of neurons, respectively, and are indicated in the figures. Statistical differences were calculated according to nonparametric tests. When significant differences were examined, $p$ values for pairwise comparisons were calculated according to two-tailed Mann-Whitney tests (for unpaired data) or Wilcoxon tests (for paired data). Comparisons between cumulative distributions were performed according to two-sample Kolmogorov-Smirnov tests. $p$ values are indicated in the legends for each figure.

\section{Results}

\section{Silencing network activity with TTX leads to enhanced LTP}

To investigate the impact of chronic silencing of a network on Hebbian plasticity, we treated cultured mouse hippocampal slices with TTX for $60 \mathrm{~h}$. After washing out the TTX, we examined LTP at Schaffer collateral-CA1 pyramidal neuron synapses. Pairing a $3 \mathrm{~Hz}$ stimulation with postsynaptic depolarization to $0 \mathrm{mV}$ in control slices reliably induced LTP, producing a significant increase in evoked EPSCs (eEPSCs; $2.74 \pm 0.39$-fold) that lasted for at least an hour postinduction (Fig. $1 A, B$ ). In contrast, TTXtreated slices exhibited much greater LTP using the same induction protocol (5.48 \pm 0.83 -fold; Fig. 1$)$. The enhancement of synaptic strength in both types of slices was fully blocked by the NMDA receptor antagonist D-APV (control: $1.10 \pm 0.13$-fold; TTX: $1.26 \pm 0.10$-fold; Fig. 1), indicating that LTP in control and TTX-treated slices is the classical NMDAR-dependent LTP reported and characterized previously (Nicoll and Malenka, 1999).

The enhanced LTP in TTX-treated slices was somewhat unexpected because chronic silencing of a network is known to induce a form of non-Hebbian plasticity - termed homeostatic synaptic plasticity - which scales up synaptic strength of all synapses to 
A
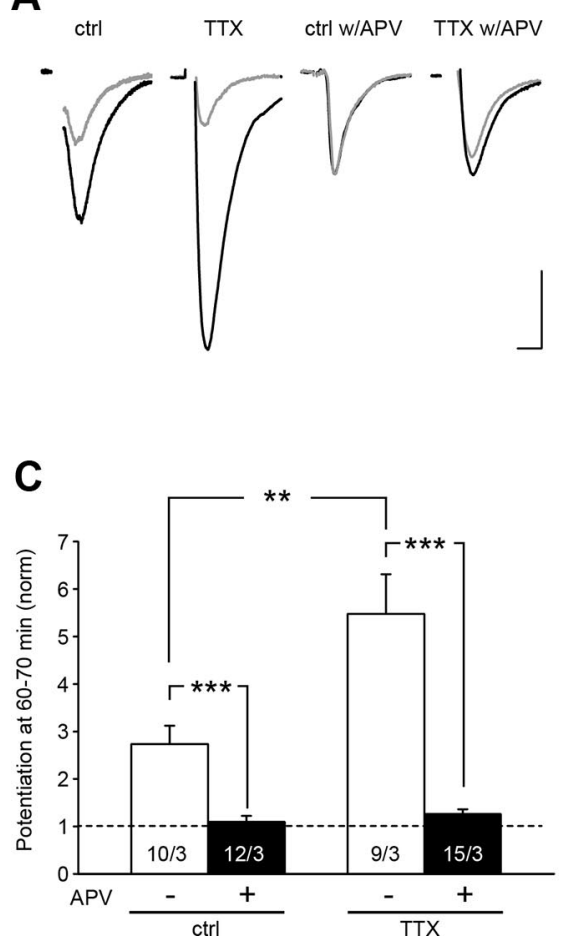

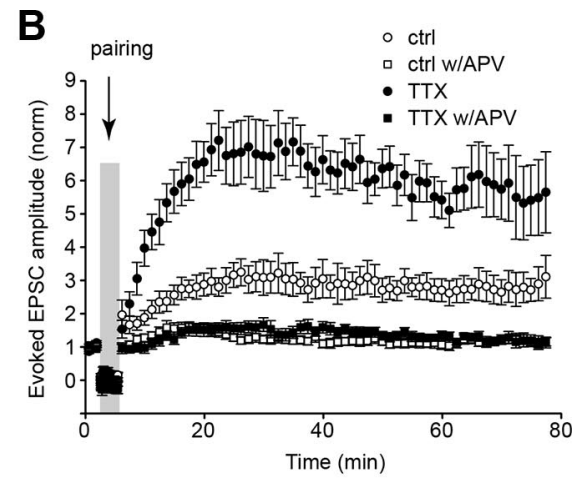

D

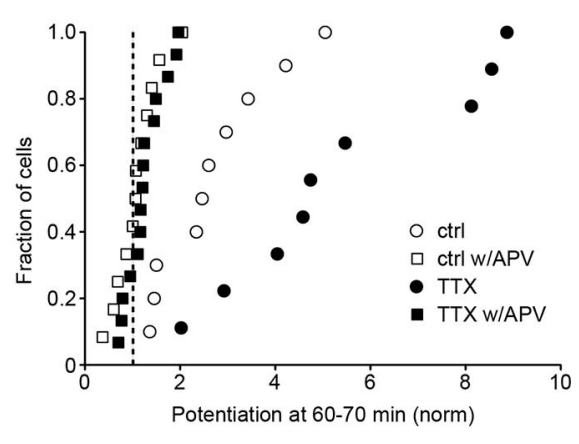

Figure 1. TTX scaling increases the magnitude of long-term potentiation. $\boldsymbol{A}$, Example traces of evoked EPSCS at CA3-CA1 pyramidal neuron synapses before (gray) and 50-60 min after (black) LTP induction in the presence or absence of APV. Examples from $60 \mathrm{~h}$ vehicle or TTX treatment are shown. Calibration: 50 pA, 10 ms. B, Average EPSCs during LTP experiments. LTP was induced in the presence or absence of bath-applied APV with the pairing protocol (see Materials and Methods) in vehicle or TTX-treated slices (TTX was washed out before recording was achieved). Compared with their baseline values, significant potentiation for the control (ctrl) group and the TTX group was observed ( $p<0.0001$, paired $t$ test; $N$ numbers are shown as number of cells/number of independent experiments). A significant difference in the magnitude of LTP was observed between the control group and the TTX $(p<0.001)$. C, Quantification of the magnitude of LTP at $60-70$ min postinduction $\left({ }^{* *} p<0.01\right.$; ${ }^{* * *} p<$ 0.001). $\boldsymbol{D}$, Cumulative distribution of the magnitude of LTP for all cells in $\boldsymbol{B}$ and $\boldsymbol{C}$.

compensate for the loss of activity (Davis, 2006; Turrigiano, 2012). Thus, one might expect that these newly strengthened synapses will have less capacity for LTP. To confirm that, in our experimental system, TTX treatment indeed caused an upregulation of synaptic strength, we examined miniature EPSCs in CA1 pyramidal neurons. Consistent with previous reports, we observed an increase in mEPSC amplitude in TTX-treated slices (control: $12.13 \pm 0.46 \mathrm{pA}$; TTX: $15.12 \pm 0.70 \mathrm{pA}$ ) without an accompanying increase in mEPSC frequency (control: $0.25 \pm$ $0.03 \mathrm{~Hz}$; TTX: $0.25 \pm 0.03 \mathrm{~Hz}$; Fig. $2 A$ ). Thus, the $60 \mathrm{~h}$ TTX treatment does indeed produce homeostatic increase in EPSCs as described previously (Turrigiano et al., 1998; Sutton et al., 2006; Echegoyen et al., 2007; Soden and Chen, 2010; Wang et al., 2011).

It has been recently proposed that mEPSCs and eEPSCs may involve different vesicle pools for transmitter release and may activate different populations of postsynaptic receptors (Ramirez and Kavalali, 2011). Because LTP was evaluated with eEPSCs, we asked whether TTX treatment also induced an increase in eEPSC amplitude. We measured input/output curves for Schaffer collateral synaptic transmission using field potential recordings in the S. radiatum. The fEPSP slope normalized to the size of the fiber volley was compared between control and TTX-treated slices at varying stimulation intensity. Although the measured synaptic strength was fairly consistent at different stimulus intensity, the TTX-treated group had a significantly higher synaptic efficacy (Fig. 2B), indicative of increased synaptic strength as a result of homeostatic synaptic plasticity. Neither the paired-pulse ratio nor the passive membrane properties of the CA1 neurons were altered (Fig. 2C,D), suggesting that, in agreement with previous findings (Turrigiano et al., 1998; Sutton et al., 2006; Soden and Chen, 2010; Wang et al., 2011), these changes are largely due to an increase in postsynaptic receptor abundance.

\section{Chronic silencing of a neural network upregulates both AMPAR- and NMDAR-mediated EPSCs}

To explore potential mechanisms underlying enhanced LTP in TTX-treated slices, we examined whether NMDAR-mediated EPSCs are also altered by activity blockade. It has been reported that TTX treatment concomitantly upregulates both AMPA and NMDA receptor-mediated responses (Watt et al., 2000). Similar to this finding, we found that TTX did not significantly alter the AMPAR/NMDAR response ratio. Instead, we observed a trend (not statistically significant) of reduced AMPAR/NMDAR response ratio in the TTX group (control: $1.19 \pm 0.09$; TTX: $1.11 \pm 0.09$; Fig. $3 A$ ). Since AMPAR responses increased as a result of synaptic scaling, this result implies that the NMDAR responses were also scaled up by TTX treatment. To directly measure whether NMDAR responses were increased at synapses, we recorded dual component mEPSCs in the absence of external $\mathrm{Mg}^{2+}$ using a previously described method (Gomperts et al., 1998; Tracy et al., 2011) (Fig. 3B). The NMDAR component was measured by subtracting the AMPAR-only component of mEPSCs in the presence of the NMDAR antagonist APV from the dual component mEPSCs taken before APV addition for each neuron. We found that both AMPAR (control: $10.99 \pm 0.41 \mathrm{pA}$; TTX: $13.40 \pm 0.69$ $\mathrm{pA}$ ) and NMDAR-mediated mEPSC (control: $2.31 \pm 0.14 \mathrm{pA}$; TTX: $3.99 \pm 0.44 \mathrm{pA}$ ) were increased by TTX treatment (Fig. 3C).

NMDAR composition in the forebrain exhibits a developmental switch from primarily NR2B-containing to primarily NR2A-containing receptors (Monyer et al., 1994; Sheng et al., 1994; Stocca and Vicini, 1998; Tovar and Westbrook, 1999; Liu et al., 2004b). NMDARs with different NR2 subunit composition have been proposed to mediate different forms of Hebbian synaptic plasticity (Liu et al., 2004a; Massey et al., 2004; Barria and Malinow, 2005; Toyoda et al., 2005). It is possible that the TTXinduced NMDAR upregulation changes the composition of postsynaptic NMDARs, thereby enhancing LTP. We therefore tested the sensitivity of the NMDAR response to the NR2B-selective antagonist ifenprodil, and found that the relative ifenprodilsensitive NMDAR response remained the same between control and TTX-treated groups (control: $33.94 \pm 8.19 \%$, TTX: $35.96 \pm$ $11.58 \%$; Fig. $4 A$ ), suggesting that chronic activity blockade does not induce changes in the synaptic NMDAR composition.

We further tested the effect of ifenprodil on pairing-induced LTP to see whether the contribution of NR2A- versus NR2Bcontaining NMDARs to the induction of LTP remains the same. Although the TTX-treated group consistently exhibited greater 
A
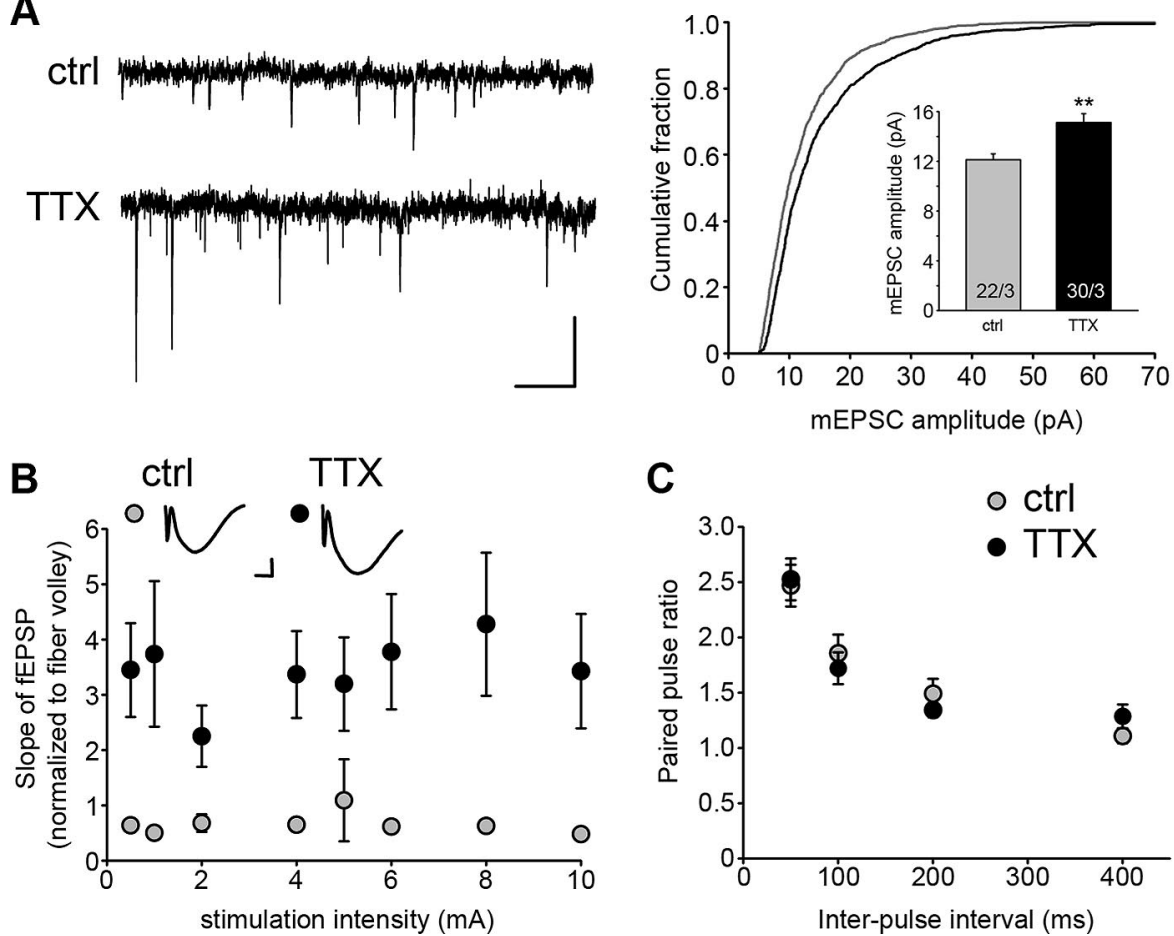

C

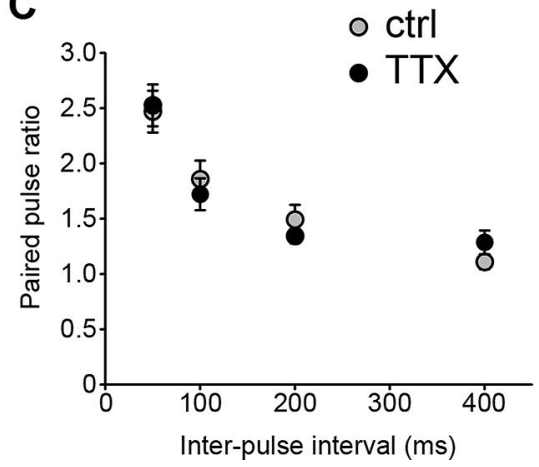

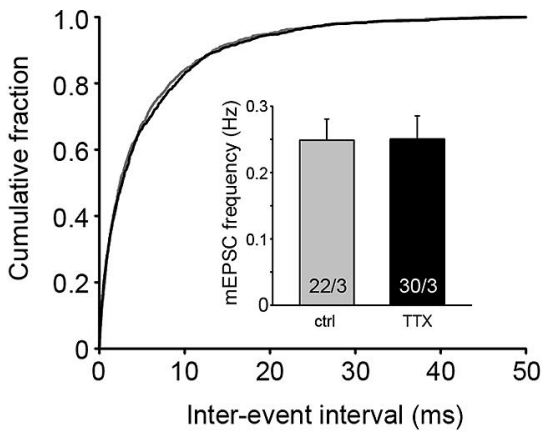

D

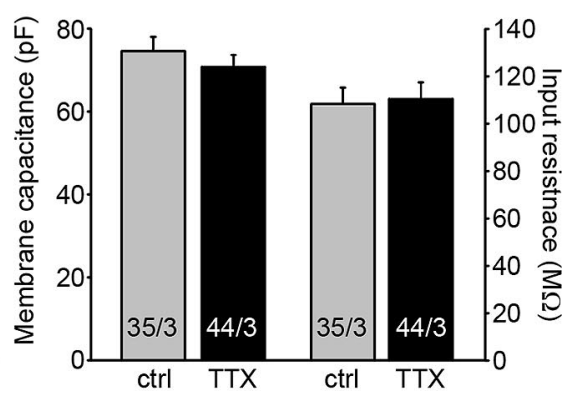

Figure 2. TTX scaling increases basal AMPA-receptor-mediated transmission. $\boldsymbol{A}$, Miniature excitatory transmission for control and TTX-treated cells. Quantification of the average miniature amplitude $\left.{ }^{* *} p<0.01\right)$ and frequency $(p>0.9)$ for control (ctrl) and TTX-treated neurons. Calibration: 10 pA, 1 s. $\boldsymbol{B}$, Evoked fEPSP input/output curve for control and TTX-treated slices across a range of stimulation intensities. Slope of the fEPSP was normalized to the presynaptic fiber volley. Significant difference was observed at all points for TTX compared with control $(p<0.001, n=$ $16-27 / 3)$. Inset, Example waveforms of fEPSP recorded from control and TTX-treated slices. Calibration: $0.1 \mathrm{mV}, 1 \mathrm{~ms}$. $C$, Paired pulse ratio for cells treated with TTX or vehicle reveals no difference in presynaptic properties $(p>0.5, n=11-13 / 3)$. $D$, Passive membrane properties of both experimental groups $(p>0.4)$.

LTP (Fig. 4B), bath-applied ifenprodil significantly reduced the magnitude of LTP in both groups (control: $2.63 \pm 0.08$, control + ifenprodil: $1.55 \pm 0.26$, TTX: $4.34 \pm 0.62$, TTX + ifenprodil: $2.56 \pm$ 0.38; Fig. $4 C$ ), and the percentage of LTP that was blocked by ifenprodil remained the same between the two groups (control: $36.22 \pm 10.7 \%$, TTX: $46.86 \pm 7.95 \%$; Fig. $4 D$ ), further confirming that no change in NMDAR composition occurred during TTX treatment.

Increase in the presence of new postsynaptically silent synapses by network silencing

It has been shown previously that some glutamatergic synapses lack AMPARs and contain only NMDARs (Isaac et al., 1995; Liao et al., 1995; Wu et al., 1996). Due to the voltage-dependent magnesium blockade of NMDARs, these synapses are functionally silent even though presynaptic glutamate release is normal. Induction of LTP not only involves strengthening existing active synapses, but can also induce insertion of AMPARs into and activation of silent synapses (Isaac et al., 1995; Liao et al., 1995). We therefore explored whether the silent synapse population is affected by chronic activity blockade, and if so, whether LTP under these conditions involves activating silent synapses.

B
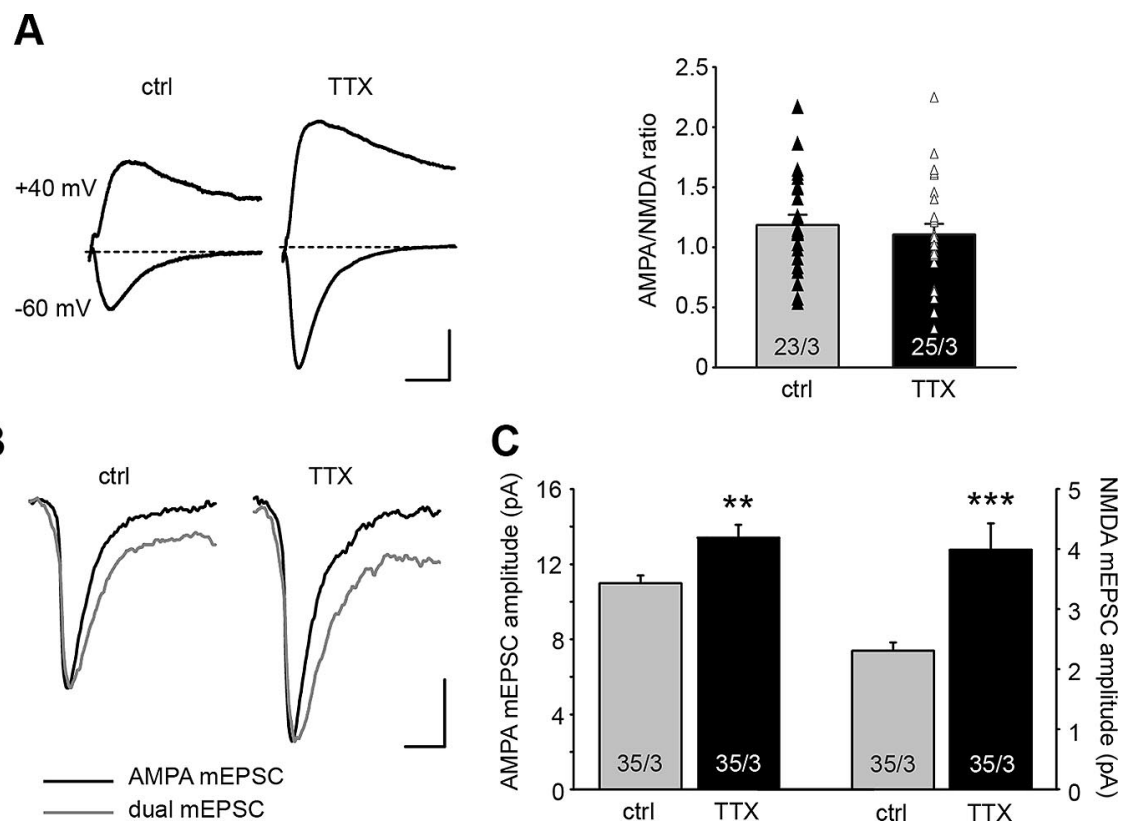

Figure 3. TTX-scaled hippocampal pyramidal neurons have increased AMPA- and NMDA-receptor-mediated transmission. $\boldsymbol{A}$, Example traces of evoked synaptic AMPA and NMDA currents and quantification of the evoked AMPA/NMDAR ratio $(p>0.5)$. Calibration: 50 pA, 20 ms. B, Example traces of dual-component mEPSCs. Calibration: 4 pA, $10 \mathrm{~ms}$. C, Quantification of the AMPAR mEPSCs and NMDAR mEPSCs $\left({ }^{* *} p<0.01,{ }^{* * *} p<0.001\right)$ for control (ctrl) and TTX cells.

To detect silent synapses, whole-cell patch-clamp recordings were obtained from CA1 pyramidal neurons. Cells were clamped at their resting membrane potential $(\sim-60 \mathrm{mV})$, and excitatory synaptic transmission was elicited with a weak stimulus that produced failures in $\sim 50 \%$ of trials. Epochs of 50 trials of transmis- 

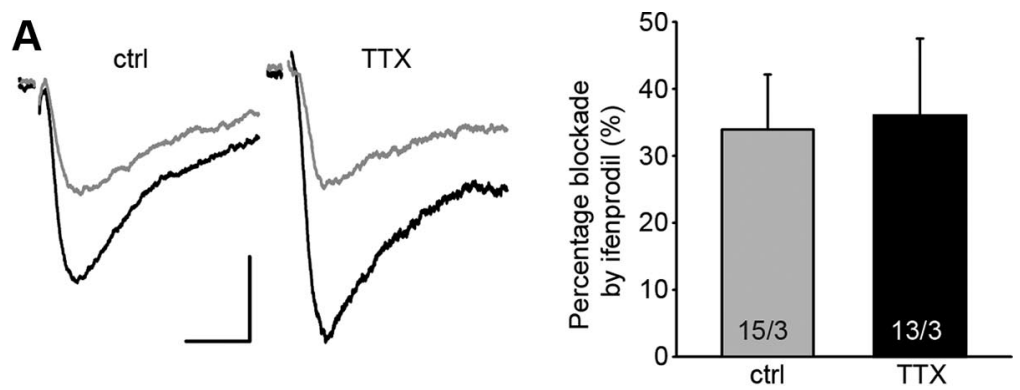

B
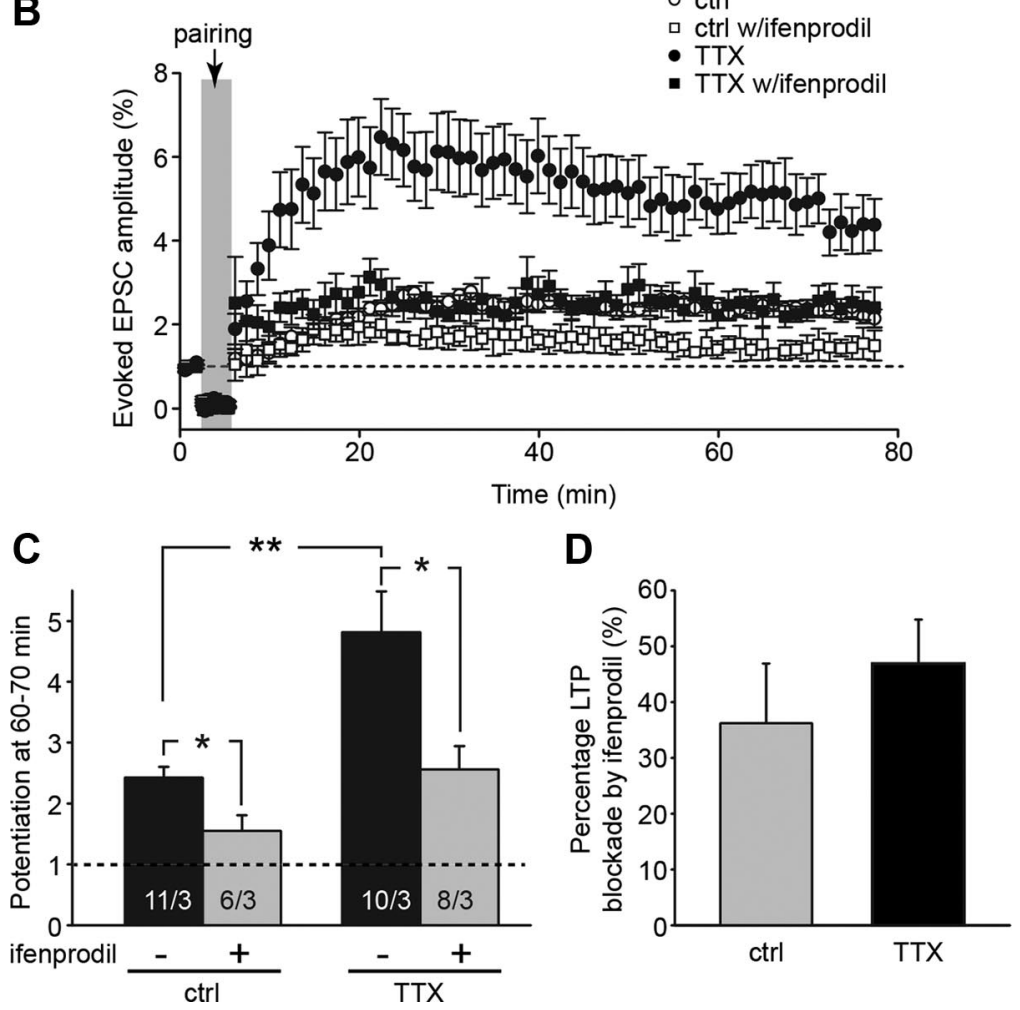

Figure 4. TTX treatment does not change synaptic NMDA receptor composition. $\boldsymbol{A}$, Example traces of evoked NMDA currents before (black) and after (gray) blockade of NR2B current via ifenprodil ( $30 \mu \mathrm{m})$. Calibration: $20 \mathrm{pA}, 40 \mathrm{~ms}$. Quantification of peak NMDA current blockade is shown for control (ctrl) and TTX-treated cells. $\boldsymbol{B}$, NMDA receptor-dependent LTP in the presence of ifenprodil for both control and TTX-treated neurons. $C$, Quantification of the magnitude of LTP in the presence and absence of ifenprodil for control and TTX-treated cells $\left({ }^{*} p<0.05 ;{ }^{* *} p<0.01\right)$. $\boldsymbol{D}$, The percentage LTP blockade by ifenprodil is comparable for the two groups $(p>0.4)$.

sion were recorded at -60 and $+40 \mathrm{mV}$ for each cell, and the failure rate at these two holding potentials was computed. In cells cultured under control condition, the failure rate was comparable between the negative and the positive holding potentials $(-60$ $\mathrm{mV}: 53.33 \pm 3.07 \%,+40 \mathrm{mV}: 54.38 \pm 4.55 \%$; Fig. $5 A, C-E)$, indicating that most synapses are active at this stage of development. However, $60 \mathrm{~h}$ TTX treatment significantly decreased the failure rate measured at $+40 \mathrm{mV}$ compared with that at $-60 \mathrm{mV}$ $(-60 \mathrm{mV}: 47.26 \pm 2.75 \%,+40 \mathrm{mV}: 20.74 \pm 5.10 \%$; Fig. $5 \mathrm{~B}, \mathrm{C}-$ $E)$, indicative of the presence of silent synapses due to chronic network inactivity.

Previous studies consistently showed that TTX treatment leads to a selective increase in mEPSC amplitude, but not frequency (Turrigiano et al., 1998; Sutton et al., 2006; Soden and Chen, 2010), indicating that synaptic scaling induced by the TTX treatment is mainly achieved by increasing the strength but not the number of active synapses. However, the above data suggest that, in addition to increasing the strength of existing active syn- apses, TTX treatment also induced formation (or selective preservation) of new synapses lacking AMPARs. The "silent" property of these new synapses makes them difficult to detect by traditional mEPSC measurements. Therefore, we decided to examine whether we can use immunocytochemistry to visualize these newly formed synapses. Double immunolabeling for the excitatory synaptic marker VGluT1 and either AMPARs (GluA1) or NMDARs (GluN1) was performed in cultured hippocampal neurons that received $48 \mathrm{~h}$ of either vehicle or TTX treatment. Synaptic GluA1 or GluN1 puncta were identified as those colocalized with VGlut1 and were quantified. Confirming previous findings, the TTX treatment increased both the synaptic GluA1 puncta size (control: $0.19 \pm 0.004 \mu \mathrm{m}^{2}$, TTX: $0.21 \pm 0.004 \mu \mathrm{m}^{2}$ ) and their integrated intensity (control: $1812.70 \pm 47.18 \mathrm{AU}$, TTX: $2302.64 \pm 73.31$ AU; Fig. $6 B$ ), indicating that individual synaptic strength was increased after chronic silencing. Similarly, synaptic GluN1 (a NMDAR subunit) puncta exhibited an enhanced size and integrated intensity (size: control: $0.15 \pm 0.003 \mu \mathrm{m}^{2}$, TTX: $0.19 \pm 0.004 \mu \mathrm{m}^{2}$; integrated intensity: control: $1147.23 \pm 33.86$ AU, TTX: 1774.05 \pm 50.21 AU; Fig. 6A, C), corroborating the observation obtained in the dual component mEPSC recordings (Fig. 3C). More importantly, we found that both the density of puncta positive for VGluT1 (control: $5.50 \pm 0.27 / 10 \mu \mathrm{m}$, TTX: $6.95 \pm 0.37 / 10 \mu \mathrm{m})$ and for synaptic GluN1 (control: $4.49 \pm 0.24 / 10 \mu \mathrm{m}$, TTX: $6.00 \pm 0.33 / 10 \mu \mathrm{m})$ were increased in the TTX-treated group (Fig. 6D,E), indicating that silencing of neuronal activity induced formation of new excitatory synapses containing NMDARs. In contrast, the synaptic GluA1 density remained the same between control and TTX-treated conditions (control: $3.29 \pm 0.15 / 10 \mu \mathrm{m}$, TTX: $3.68 \pm 0.17 / 10 \mu \mathrm{m}$; Fig. $6 E$ ), suggesting that the newly formed synapses lacked AMPARs, and therefore were functionally silent. Consistent with these observations, we found that the percentage vGluT1 puncta containing GluA1 decreased from $61.52 \pm 4.13 \%$ for the control group to $45.23 \pm 4.63 \%$ for the TTX-treated group $(p<0.05)$, reflecting the increase in silent synapses after TTX treatment. In contrast, the percentage vGluT1 puncta containing GluN1 was $59.56 \pm 4.44 \%$ for the control group and $50.3 \pm 6.88 \%$ for the TTX group $(p>0.22)$. The lack of significant change in the percentage of GluN1 containing VGluT1 agrees well with the notion that newly formed synapses contain NMDA receptors.

LTP induction in TTX-treated slices converts silent synapses to active ones

Might the emergence of silent synapses following TTX treatment cause the enhanced magnitude of LTP? In other words, does the 
A

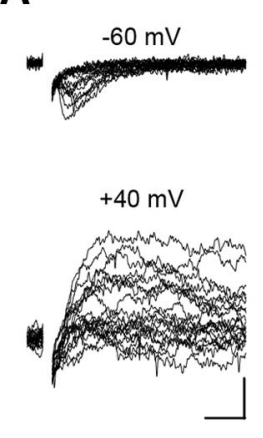

ctrl

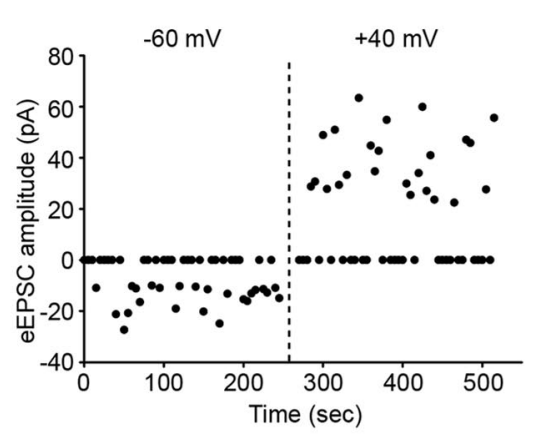

B

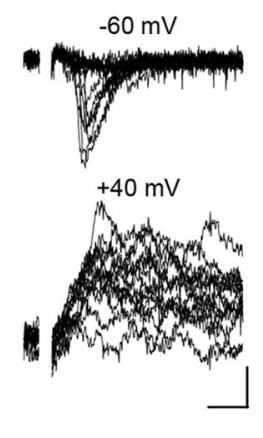

TTX

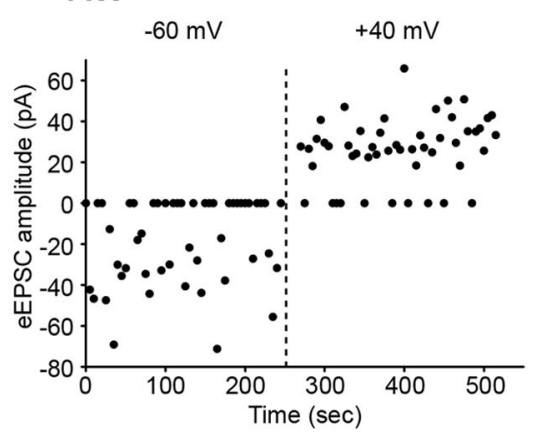

C

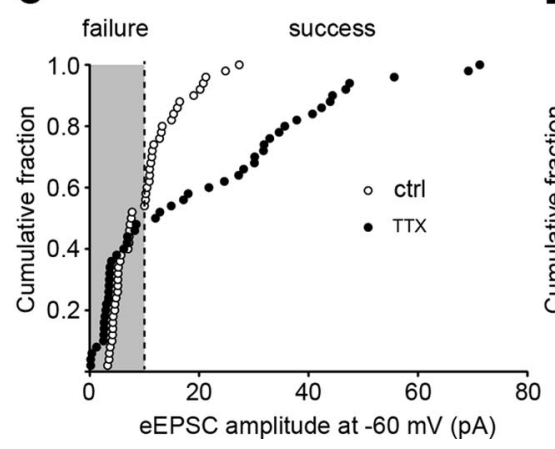

D
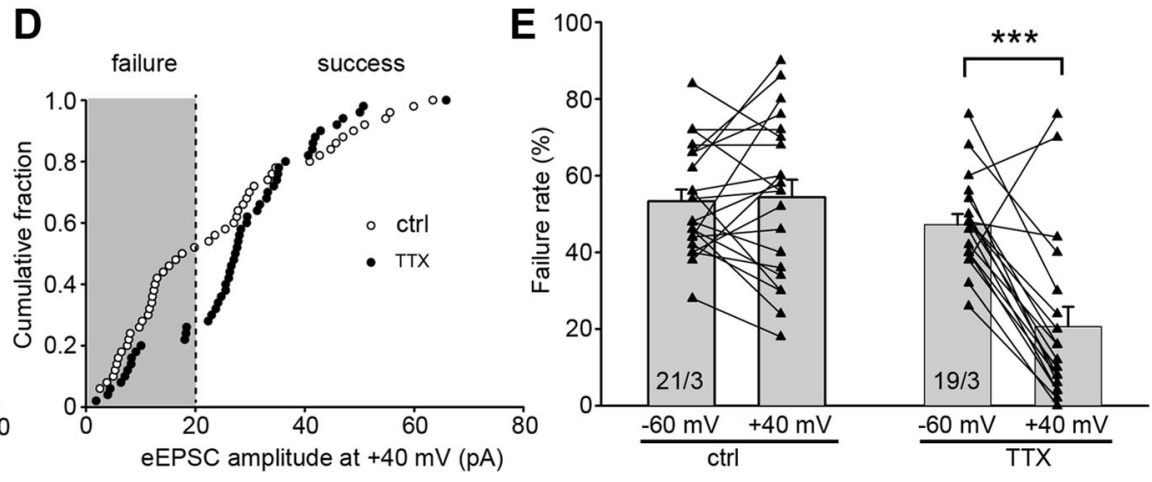

Figure 5. TTX treatment promotes silent synapse formation. $A$, Example traces and scatter plot of evoked EPSCs from one control pyramidal neuron at -60 and $+40 \mathrm{mV}$ holding potentials. Failed events were assigned with an amplitude of $0 \mathrm{pA}$ for ease of visualization. $B$, Same as $A$, except the recordings were done in a TTX-treated neuron. Calibration: $A, B, 20 \mathrm{pA}, 10 \mathrm{~ms}$. C, Cumulative amplitude histogram of the eEPSC amplitude at $-60 \mathrm{mV}$ from the control (ctrl) and TTX-treated cells shown in $\boldsymbol{A}$ and $\boldsymbol{B}$. Note the threshold for success is $10 \mathrm{pA}$. $\boldsymbol{D}$, Cumulative amplitude histogram of the eEPSC amplitude at $+40 \mathrm{mV}$ from the two cells shown in $\boldsymbol{A}$ and $\boldsymbol{B}$. Note the threshold for success is $20 \mathrm{pA}$. $\boldsymbol{E}$, Quantification of failure rate of evoked response for control and TTX-treated cells at -60 and $+40 \mathrm{mV}$ holding potentials. Failure rate is calculated from 50 sweeps per cell. Significant reduction in failure rate was observed for TTX-treated cells $\left({ }^{* * *} p<0.001\right)$.

LTP induction in TTX-treated slices lead to AMPAR insertion and functional activation of silent synapses produced by the TTX treatment? If this were true, one might predict that the mEPSC frequency in the TTX-treated group should increase as a result of LTP, while that of the control group should remain the same because there are relatively few silent synapses in control slices. We therefore induced LTP in control and TTX-treated groups and compared the mEPSC amplitude and frequency in the affected neurons before and 50-60 min after LTP induction. As expected, baseline recordings from the TTX-treated group exhibited a higher mEPSC amplitude compared with the baseline of the control group (control: $10.14 \pm 0.35 \mathrm{pA}$, TTX: $11.68 \pm 0.49$ pA; Fig. $7 A, B)$. LTP induction led to no significant increase in mEPSC amplitude in either group (control-LTP: $10.95 \pm 0.91$ pA, TTX-LTP: $14.17 \pm 1.62$ pA; Fig. $7 A, B$ ). This is most likely because the induction of LTP is only specific for a subset of synapses that are stimulated, whereas mEPSC recordings sample all synapses for a given cell. The majority of synapses on the recorded neuron did not undergo LTP, but contributed to the average amplitude of mEPSC and therefore masked the increase in the subset of synapses. However, despite this masking effect, we observed a significant increase in the mEPSC frequency in the TTX-LTP group compared with the TTX-baseline group (TTX: $0.29 \pm 0.03 \mathrm{~Hz}$, TTX-LTP: $0.54 \pm 0.07 \mathrm{~Hz}$; Fig. $7 \mathrm{~A}, \mathrm{C}$ ), indicative of recruiting previously silent synapses into the active synapse pool. This effect is specific for the TTX-treated group, as the control slices did not exhibit an increase in mEPSC frequency after LTP induction (control: $0.27 \pm 0.04 \mathrm{~Hz}$, control-LTP: $0.29 \pm 0.04 \mathrm{~Hz}$; Fig. 7 A,C) (Cormier and Kelly, 1996). The increase in mEPSC frequency in the TTX-LTP group is not sup- ported by potential increase in presynaptic release probability after LTP as the paired-pulse ratio does not differ between any of these groups (Fig. 7D).

Finally, to further examine whether LTP induction in the TTX-treated slices converts silent synapses into active synapses, we examined the failure rate 50-60 min after LTP induction in both control and TTX-treated neurons. In contrast to the failure rate reduction from holding potential of -60 to $+40 \mathrm{mV}$ in TTX-treated neurons (Fig. 5C), the failure rate remained the same between -60 and $+40 \mathrm{mV}$ in TTX-LTP neurons (control $-60 \mathrm{mV}: 58.00 \pm 3.70 \%$, control $+40 \mathrm{mV}: 62.46 \pm 5.52 \%$, TTX $-60 \mathrm{mV}: 54.98 \pm 4.00 \%$, TTX $+40 \mathrm{mV}: 58.00 \pm 4.13 \%$; Fig. $7 E$ ), indicating that most silent synapses had been converted into active synapses.

\section{Discussion}

In this study, we show that a neural network can compensate for the lack of synaptic activity in two parallel ways: by increasing the synaptic strength of existing synapses and by promoting emergence of new synapses (Fig. 8). We demonstrated the increased strength of existing synapses by an increased AMPAR mEPSC amplitude, an increased I-O relation of fEPSPs, and an increased synaptic AMPAR puncta size and integrated intensity. We also observed an increased NMDAR component of mEPSCs, an unchanged AMPA/NMDA ratio of evoked EPSCs, and an increased synaptic GluN1 puncta size and integrated intensity, documenting that both synaptic AMPAR and NMDAR abundance are increased after TTX treatment, as previously reported (Watt et al., 2000). Interestingly, we also found that the synaptic VGlut1 and GluN1 density increased significantly after TTX treatment, sug- 
A
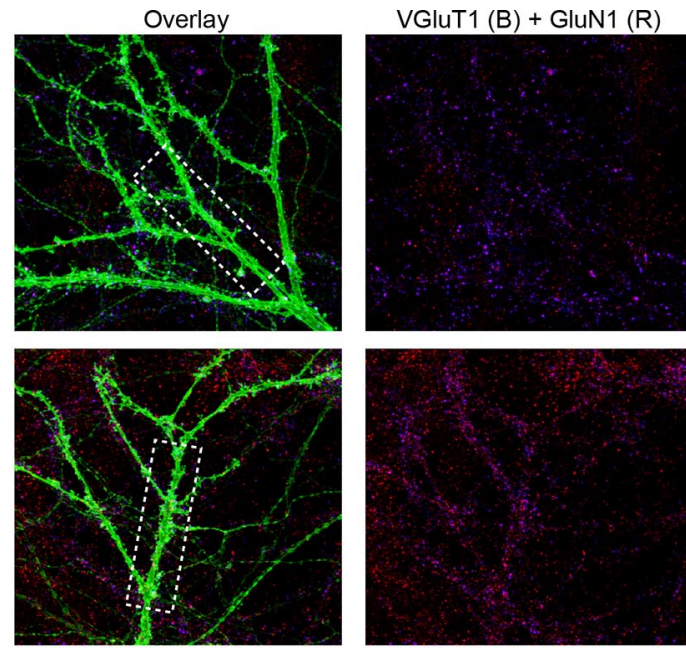

B
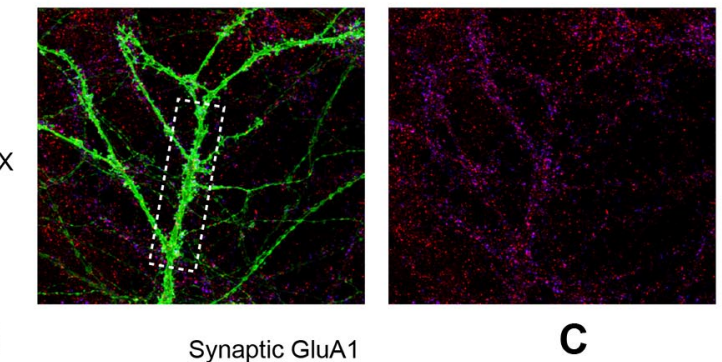

C
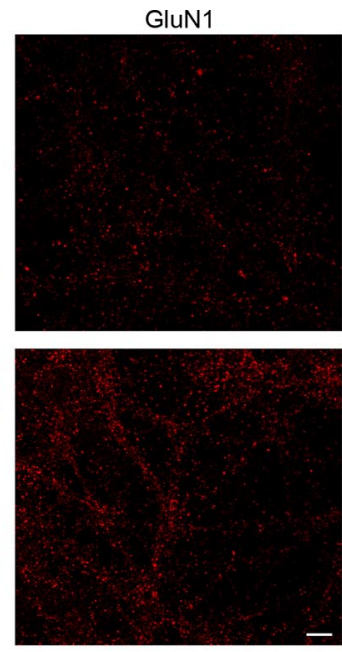

Synaptic GluN1
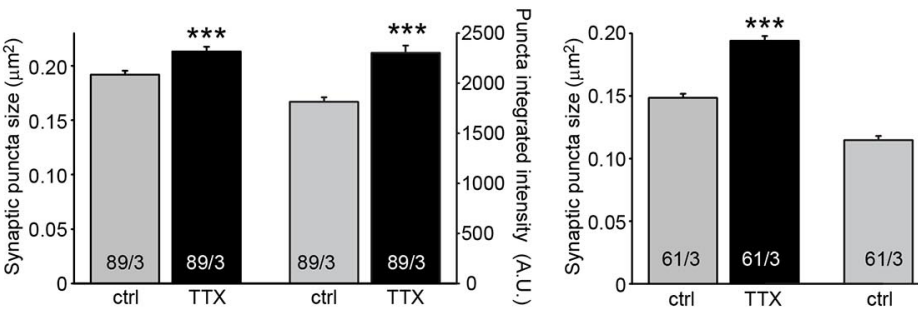

D

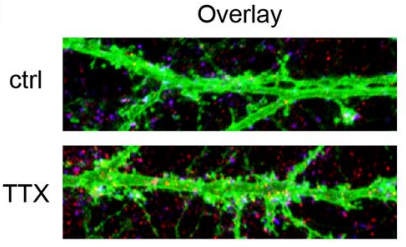

VGluT1 (B) + GluN1 (R)
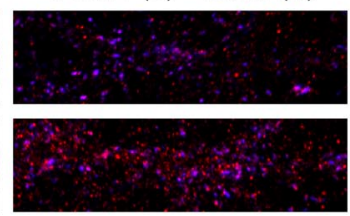

$\mathbf{E}$
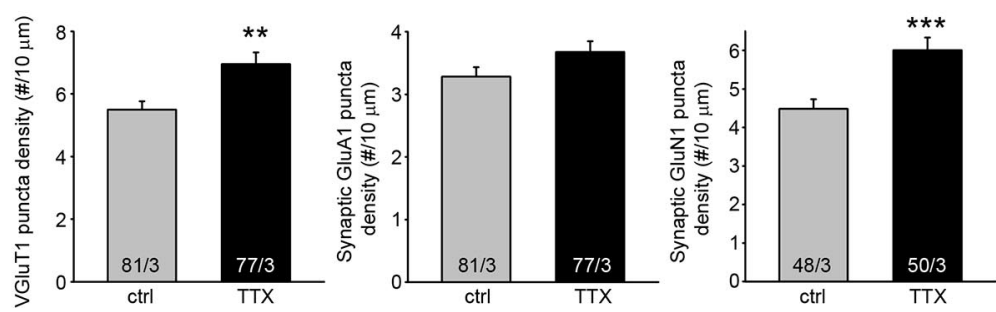

Figure 6. TTX treatment increased NMDAR- but not AMPAR-containing synapses. $\boldsymbol{A}$, Immunostaining of VGluT1 and GluN1 in 14 DIV primary hippocampal cultures treated with vehicle (ctrl) or TTX for $48 \mathrm{~h}$. Scale bar, $10 \mu \mathrm{m}$. B, Quantification of synaptic (VGluT1-positive) GluA1 puncta size and integrated intensity ${ }^{* * *} p<0.001 ; N$ number indicates number of neurons/number of independent experiments). C, Quantification of synaptic GluN1 puncta size and integrated intensity $\left({ }^{* * *} p<0.001\right)$. D, Zoomed in images of VGluT1 and GluN1 staining taken from the boxed areas in $\boldsymbol{A}$. Scale bar, $5 \mu \mathrm{m} . \boldsymbol{E}$, Quantification of density of all excitatory synapses (VGluT1 density), AMPAR-containing synapses (synaptic GluA1 density), and NMDAR-containing synapses (synaptic GluN1 density) ${ }^{* *} p<0.01 ;{ }^{* *} p<0.001 ; N$ number indicate number of neurons/number of independent experiments).

gesting emergence of new synapses as a result of the inactivation of the network. The fact that the synaptic GluA1 density did not increase concomitantly, and that the mEPSC frequency failed to increase after the TTX treatment, indicate that these newly formed synapses lack AMPARs, and are therefore functionally silent. Presence of silent synapses after TTX treatment is further supported by the reduced failure rate of eEPSCs at depolarizing holding potentials.

What is the functional consequence of silent synapse formation after network inactivity? We found that LTP induction in TTX-treated hippocampal slices activates these silent new syn-

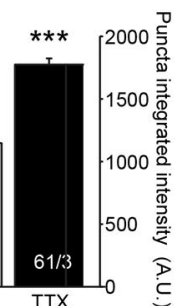

apses through synaptic insertion of AMPARs, which is supported by the observation that the mEPSC frequency was increased and the failure rate of eEPSCs was no longer different between positive and negative holding potentials after LTP induction in TTX-treated slices. As a consequence of activating these newly emerged silent synapses, the LTP magnitude was greatly enhanced in TTX-treated slices (Fig. 8). Therefore, although these new synapses do not contribute immediately to the apparent synaptic connectivity as a direct consequence of homeostatic plasticity, they can be switched on by activity patterns that induce LTP, resulting in stronger modifications of the activated inputs, i.e., in an apparent increase in LTP. In conclusion, homeostatic synaptic plasticity not only compensates for the lack of network activity, it also acts as a form of metaplasticity that enables more robust Hebbian plasticity to occur (Fig. 8).

In compensating for the reduced synaptic activity caused by the TTX treatment, NMDAR abundance evidently is enhanced at existing active synapses (Fig. 3) (Watt et al., 2000). Previous studies (Nakayama et al., 2005; Lee et al., 2010) reported a switch in NMDAR composition as a result of reduced activity. However, we did not observe such a change- - the sensitivity of synaptic NMDAR response to ifenprodil remained the same after TTX treatment. The difference in our observations may be due to differences in experimental conditions. Our study was conducted in young hippocampal slices where NR2B still contributes significantly to synaptic NMDAR responses (Fig. 4), which may preclude further addition of NR2B-containing NMDARs to the synapses. Additionally, in the study by Nakayama and colleagues (2005), ifenprodil-sensitivity was examined with exogenously applied NMDA, which activates extrasynaptic as well as synaptic NMDARs. Therefore, the observed change in NMDAR composition could represent the changes in extrasynaptic surface receptors. In the study by Lee and colleagues (2010), silencing of single synapses was achieved with tetanus toxin light chain (TeNT) expression in individual neurons sparsely distributed in the culture. In this case, no synaptic vesicle fusion could occur at the few synapses receiving input from the transfected neurons expressing TeNT, which creates a completely silent synapse without any miniature synaptic transmission. TTX treatment, in contrast, blocks network firing and synchronous release but preserves miniature synaptic transmission. For individual synapses, these two approaches exert a fundamentally different influence on synaptic activity. Another difference between the two approaches is that silencing single synapses has little impact on the overall neuronal excitability while TTX treatment 
shuts down entire network activity while leaving miniature synaptic transmission intact. Recent progress in the homeostatic synaptic plasticity field suggest that the mechanisms mediating local versus global homeostatic synaptic plasticity are distinct from each other (Yu and Goda, 2009; Turrigiano, 2012). It is highly likely that although network inactivity (TTXtreatment) increases the surface delivery of NR2B-containing NMDARs, their synaptic delivery requires a completely silenced postsynaptic response. The increased NR2B-containing NMDARs at silenced synapses were thought to be responsible for the reduced LTP induction threshold at these synapses (Lee et al., 2010). In our hands, the enhanced LTP magnitude was not due to increased synaptic NR2B-containing NMDARs. We did not observe increased sensitivity of synaptic NMDAR response to ifenprodil (Fig. 4A), and we also showed that the percentage of LTP blocked by ifenprodil remained the same with or without TTX treatment (Fig. $4 D)$. This result indicates that both NR2A- and NR2B-containing NMDARs contribute to LTP induction in our system (Müller et al., 2009), and that their relative contribution is similar between synapses that have a history of normal or reduced activity.

Previous studies suggested differential contributions of NR2A- and NR2Bcontaining NMDARs to LTP and LTD, although the details remain controversial (Tang et al., 1999; Liu et al., 2004a; Massey et al., 2004; Barria and Malinow, 2005; Toyoda et al., 2005; Morishita et al., 2007). In any case, we do not believe that the enhanced LTP we observed in TTXtreated hippocampal slices was due to a switch in NMDAR composition because of a lack of change in ifenprodil-mediated inhibition (see above). Instead, we propose that the newly emerged silent synapses are the basis for the observed metaplasticity. These new synapses are initially functionally silent, and therefore not detectable during basal synaptic transmission because the neurons seldom become depolarized enough to dislodge magnesium from the NMDAR pore at these synapses, thus preventing overexcitation as a result of homeostatic compensation of reduced network activity. During LTP induction, however, postsynaptic depolarization activates all synaptic NMDARs, including those that are at silent synapses, thus inducing AMPAR insertion into both silent and active synapses (Isaac et al., 1995; Liao et al., 1995). Turning on silent synapses, in addition to
A

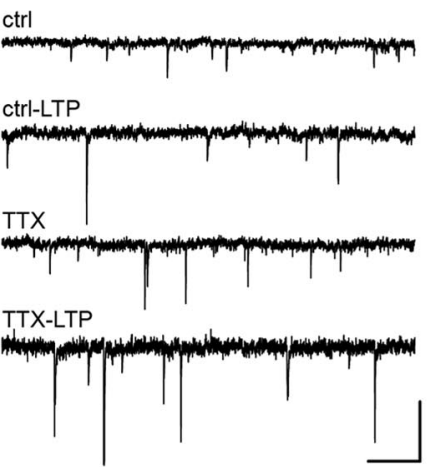

B

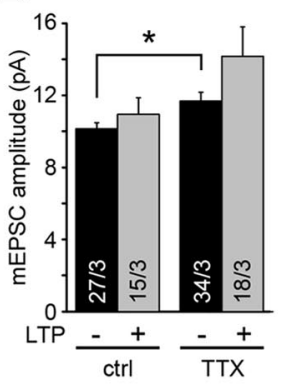

C

D
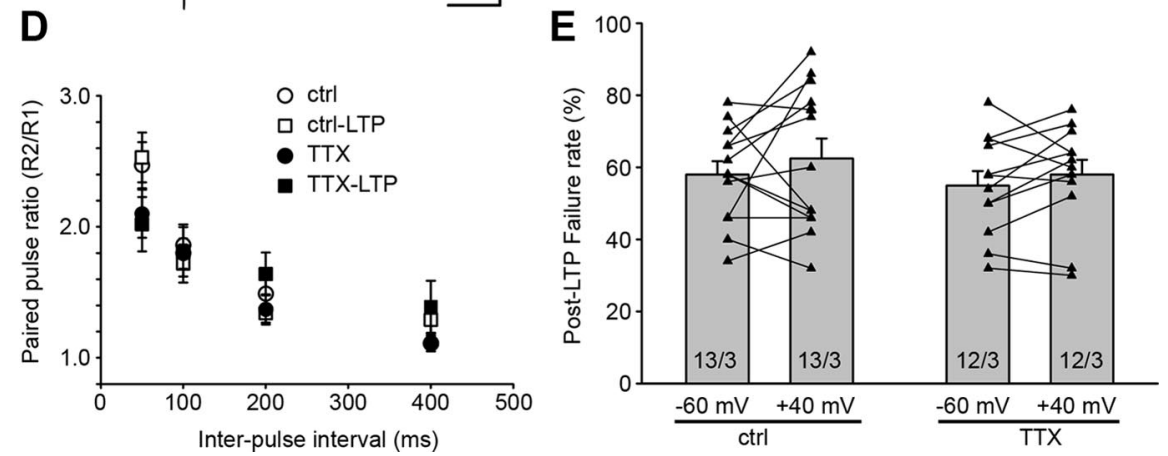

Figure 7. LTP induction in TTX-treated neurons converts silent synapses to active ones. $A$, Example mEPSC traces from control (ctrl) and TTX-treated cells during baseline and post-LTP induction period. Calibration: $20 \mathrm{pA}, 1 \mathrm{~s} . \mathrm{B}, \mathrm{C}$, Quantification of mEPSC amplitude and frequency during baseline and post-LTP induction period in control and TTX-treated cells $\left({ }^{*} p<0.05\right.$; ${ }^{* *} p<$ 0.001). $\boldsymbol{D}$, Quantification of paired-pulse ratio during baseline and after induction for control cells ( $n=14$ and 13 , respectively) and TTX-treated cells ( $n=11$ and 12 , respectively). $\boldsymbol{E}$, Quantification of failure rate for control and TTX-treated cells following LTP induction at -60 and $+40 \mathrm{mV}$ holding potentials.
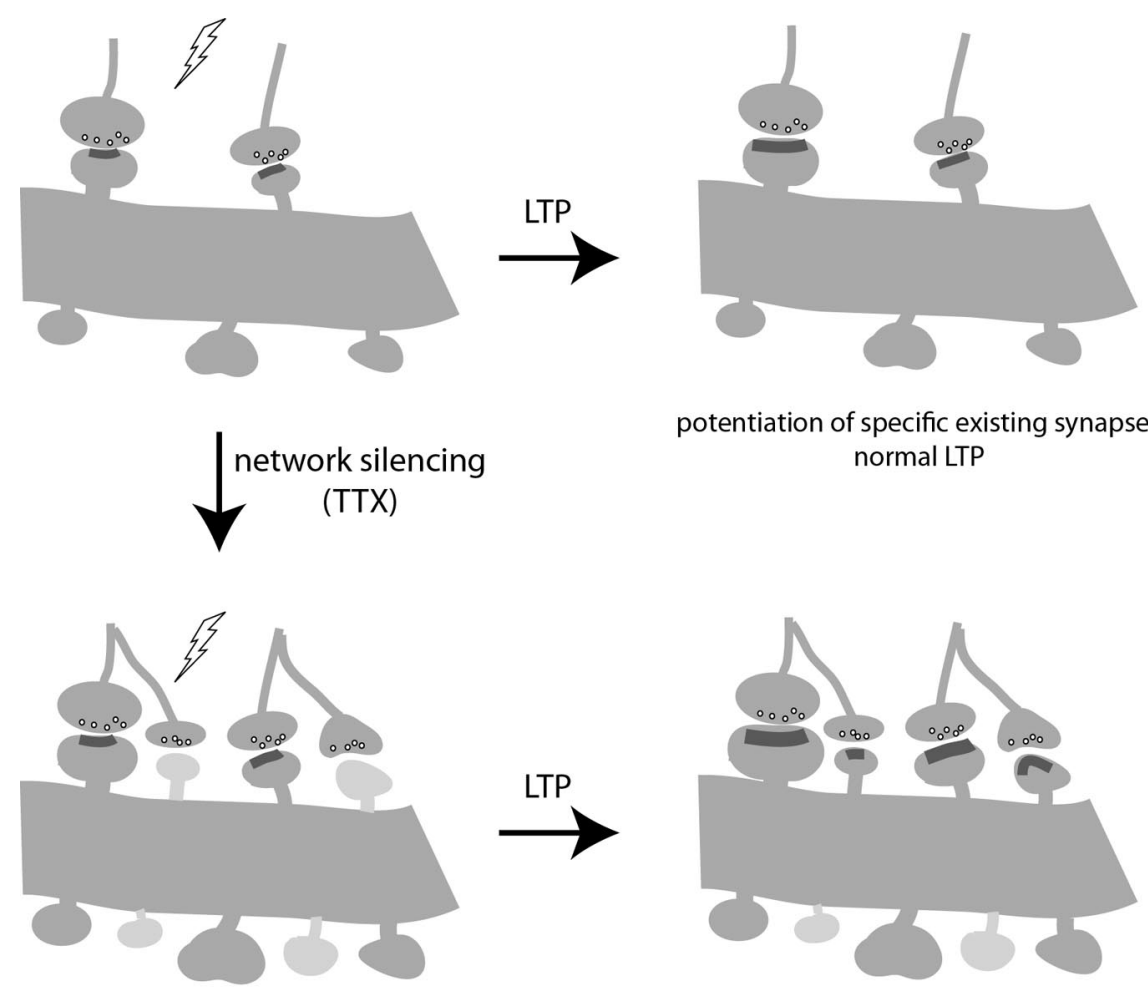

upscaling of all existing synapses emergence of new silent synapses meta-plastic state potentiation of specific existing synapses normal LTP

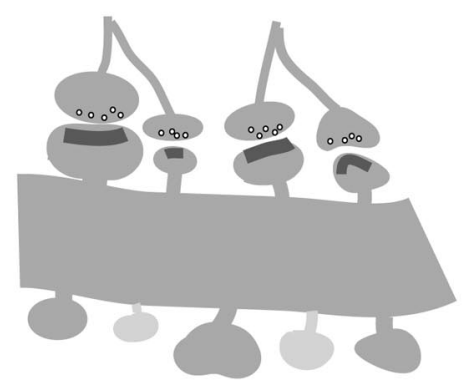

potentiation of specific existing synapses activation of specific silent synapses increased LTP

Figure 8. A schematic diagram depicting the mechanism by which network silencing influences LTP. 
potentiation of existing active synapses, leads to a striking increase in glutamatergic synaptic transmission at activated inputs that manifests as increased LTP.

It is well accepted that the history of a synapse's activity determines its current state and its ability to undergo plasticity, a phenomenon referred to as metaplasticity (Abraham and Bear, 1996). Although changes in NMDAR subunit composition has been the prevailing mechanism for the sliding threshold model of metaplasticity (Yashiro and Philpot, 2008), more recent studies show that a number of factors can influence the state of a synapse as priming factors, and therefore are involved in the metaplasticity in a broader sense that primes LTP/LTD at synapses. In addition to the above-mentioned synaptic NMDAR subunit composition, the phosphorylation state of the AMPARs (Lee et al., 2000), the ratio of CaMKII $\alpha / \beta$ (Thiagarajan et al., 2007), presynaptic endocannabinoid receptors (Chevaleyre and Castillo, 2004), as well as the state of various neuromodulator receptors (Scheiderer et al., 2004; Seol et al., 2007; Lee et al., 2010; Guo et al., 2012; Huang et al., 2012) have all been shown to act either alone or together with changes in NMDAR subunit composition as mechanisms for metaplasticity. Although different mechanisms may be involved, our study and others (Lee et al., 2010) support the notion that homeostatic synaptic plasticity acts as a form of metaplasticity. By itself, it does not change synaptic connectivity beyond the original levels, but promotes subsequent Hebbian plasticity in an input- and experience-specific manner. In vivo evidence for such metaplasticity comes from the finding that ocular dominance plasticity in adult rats can be restored by dark exposure (He et al., 2007). Ocular dominance plasticity is a form of critical period plasticity where brief deprivation of patterned vision to one eye in development leads to a rapid shift in the ocular dominance of neurons in the binocular cortex away from the deprived eye. Like critical period plasticity of other sensory modalities, ocular dominance plasticity shares many key molecular players that are required for Hebbian plasticity and is even thought to be potentially mediated by Hebbian synaptic plasticity (Bear and Rittenhouse, 1999; Berardi et al., 2003; Taha and Stryker, 2005; Smith et al., 2009; Hensch, 2005). As the critical period closes, the window for synaptic modification based solely on sensory experience closes as well. This provides structural and functional stability for adult cortical circuitry, but also restricts the recovery of function from a compromised input due to early life experience. Although it remains to be investigated whether dark rearing, which induces homeostatic upscaling in the layer 2/3 neurons of visual cortex (Desai et al., 2002; Goel and Lee, 2007), also induces new silent synapse formation, it is likely that similar mechanisms could be involved in subsequently restoring ocular dominance plasticity by changing the threshold and/or magnitude of Hebbian plasticity. Our study provides a mechanism by which extreme sensory deprivation in adult animals may cause drastic remodeling of circuitry in an otherwise structurally stable system, thus restoring a certain degree of critical period plasticity.

\section{References}

Abraham WC, Bear MF (1996) Metaplasticity: the plasticity of synaptic plasticity. Trends Neurosci 19:126-130. CrossRef Medline

Barria A, Malinow R (2005) NMDA receptor subunit composition controls synaptic plasticity by regulating binding to CaMKII. Neuron 48:289-301. CrossRef Medline

Bear MF, Rittenhouse CD (1999) Molecular basis for induction of ocular dominance plasticity. J Neurobiol 41:83-91. CrossRef Medline

Berardi N, Pizzorusso T, Ratto GM, Maffei L (2003) Molecular basis of plasticity in the visual cortex. Trends Neurosci 26:369-378. CrossRef Medline
Chevaleyre V, Castillo PE (2004) Endocannabinoid-mediated metaplasticity in the hippocampus. Neuron 43:871-881. CrossRef Medline

Cormier RJ, Kelly PT (1996) Glutamate-induced long-term potentiation enhances spontaneous EPSC amplitude but not frequency. J Neurophysiol 75:1909-1918. Medline

Davis GW (2006) Homeostatic control of neural activity: from phenomenology to molecular design. Annu Rev Neurosci 29:307-323. CrossRef Medline

Desai NS, Cudmore RH, Nelson SB, Turrigiano GG (2002) Critical periods for experience-dependent synaptic scaling in visual cortex. Nat Neurosci 5:783-789. Medline

Echegoyen J, Neu A, Graber KD, Soltesz I (2007) Homeostatic plasticity studied using in vivo hippocampal activity-blockade: synaptic scaling, intrinsic plasticity and age-dependence. PLoS One 2:e700. CrossRef Medline

Gähwiler BH, Capogna M, Debanne D, McKinney RA, Thompson SM (1997) Organotypic slice cultures: a technique has come of age. Trends Neurosci 20:471-477. CrossRef Medline

Goel A, Lee HK (2007) Persistence of experience-induced homeostatic synaptic plasticity through adulthood in superficial layers of mouse visual cortex. J Neurosci 27:6692-6700. CrossRef Medline

Gomperts SN, Rao A, Craig AM, Malenka RC, Nicoll RA (1998) Postsynaptically silent synapses in single neuron cultures. Neuron 21:1443-1451. CrossRef Medline

Guo Y, Huang S, de Pasquale R, McGehrin K, Lee HK, Zhao K, Kirkwood A (2012) Dark exposure extends the integration window for spike-timingdependent plasticity. J Neurosci 32:15027-15035. CrossRef Medline

He HY, Ray B, Dennis K, Quinlan EM (2007) Experience-dependent recovery of vision following chronic deprivation amblyopia. Nat Neurosci 10: 1134-1136. CrossRef Medline

Hensch TK (2005) Critical period mechanisms in developing visual cortex. Curr Top Dev Biol 69:215-237. CrossRef Medline

Huang S, Treviño M, He K, Ardiles A, Pasquale Rd, Guo Y, Palacios A, Huganir R, Kirkwood A (2012) Pull-push neuromodulation of LTP and LTD enables bidirectional experience-induced synaptic scaling in visual cortex. Neuron 73:497-510. CrossRef Medline

Isaac JT, Nicoll RA, Malenka RC (1995) Evidence for silent synapses: implications for the expression of LTP. Neuron 15:427-434. CrossRef Medline

Lee HK, Barbarosie M, Kameyama K, Bear MF, Huganir RL (2000) Regulation of distinct AMPA receptor phosphorylation sites during bidirectional synaptic plasticity. Nature 405:955-959. CrossRef Medline

Lee MC, Yasuda R, Ehlers MD (2010) Metaplasticity at single glutamatergic synapses. Neuron 66:859-870. CrossRef Medline

Liao D, Hessler NA, Malinow R (1995) Activation of postsynaptically silent synapses during pairing-induced LTP in CA1 region of hippocampal slice. Nature 375:400-404. CrossRef Medline

Liu L, Wong TP, Pozza MF, Lingenhoehl K, Wang Y, Sheng M, Auberson YP, Wang YT (2004a) Role of NMDA receptor subtypes in governing the direction of hippocampal synaptic plasticity. Science 304:1021-1024. CrossRef Medline

Liu XB, Murray KD, Jones EG (2004b) Switching of NMDA receptor 2A and $2 \mathrm{~B}$ subunits at thalamic and cortical synapses during early postnatal development. J Neurosci 24:8885-8895. CrossRef Medline

Massey PV, Johnson BE, Moult PR, Auberson YP, Brown MW, Molnar E, Collingridge GL, Bashir ZI (2004) Differential roles of NR2A and NR2B-containing NMDA receptors in cortical long-term potentiation and long-term depression. J Neurosci 24:7821-7828. CrossRef Medline

Monyer H, Burnashev N, Laurie DJ, Sakmann B, Seeburg PH (1994) Developmental and regional expression in the rat brain and functional properties of four NMDA receptors. Neuron 12:529-540. CrossRef Medline

Morishita W, Lu W, Smith GB, Nicoll RA, Bear MF, Malenka RC (2007) Activation of NR2B-containing NMDA receptors is not required for NMDA receptor-dependent long-term depression. Neuropharmacology 52:71-76. CrossRef Medline

Müller T, Albrecht D, Gebhardt C (2009) Both NR2A and NR2B subunits of the NMDA receptor are critical for long-term potentiation and long-term depression in the lateral amygdala of horizontal slices of adult mice. Learn Mem 16:395-405. CrossRef Medline

Nakayama K, Kiyosue K, Taguchi T (2005) Diminished neuronal activity increases neuron-neuron connectivity underlying silent synapse formation and the rapid conversion of silent to functional synapses. J Neurosci 25:4040-4051. CrossRef Medline 
Nicoll RA, Malenka RC (1999) Expression mechanisms underlying NMDA receptor-dependent long-term potentiation. Ann N Y Acad Sci 868:515525. CrossRef Medline

Pozo K, Goda Y (2010) Unraveling mechanisms of homeostatic synaptic plasticity. Neuron 66:337-351. CrossRef Medline

Ramirez DM, Kavalali ET (2011) Differential regulation of spontaneous and evoked neurotransmitter release at central synapses. Curr Opin Neurobiol 21:275-282. CrossRef Medline

Scheiderer CL, Dobrunz LE, McMahon LL (2004) Novel form of long-term synaptic depression in rat hippocampus induced by activation of alpha 1 adrenergic receptors. J Neurophysiol 91:1071-1077. Medline

Seol GH, Ziburkus J, Huang S, Song L, Kim IT, Takamiya K, Huganir RL, Lee HK, Kirkwood A (2007) Neuromodulators control the polarity of spiketiming-dependent synaptic plasticity. Neuron 55:919-929. CrossRef Medline

Sheng M, Cummings J, Roldan LA, Jan YN, Jan LY (1994) Changing subunit composition of heteromeric NMDA receptors during development of rat cortex. Nature 368:144-147. CrossRef Medline

Smith GB, Heynen AJ, Bear MF (2009) Bidirectional synaptic mechanisms of ocular dominance plasticity in visual cortex. Philos Trans R Soc Lond B Biol Sci 364:357-367. CrossRef Medline

Soden ME, Chen L (2010) Fragile X protein FMRP is required for homeostatic plasticity and regulation of synaptic strength by retinoic acid. J Neurosci 30:16910-16921. CrossRef Medline

Stocca G, Vicini S (1998) Increased contribution of NR2A subunit to synaptic NMDA receptors in developing rat cortical neurons. J Physiol 507:13-24.

Sutton MA, Ito HT, Cressy P, Kempf C, Woo JC, Schuman EM (2006) Miniature neurotransmission stabilizes synaptic function via tonic suppression of local dendritic protein synthesis. Cell 125:785-799. CrossRef Medline

Taha SA, Stryker MP (2005) Molecular substrates of plasticity in the developing visual cortex. Prog Brain Res 147:103-114. CrossRef Medline

Tang YP, Shimizu E, Dube GR, Rampon C, Kerchner GA, Zhuo M, Liu G,
Tsien JZ (1999) Genetic enhancement of learning and memory in mice. Nature 401:63-69. CrossRef Medline

Thiagarajan TC, Lindskog M, Malgaroli A, Tsien RW (2007) LTP and adaptation to inactivity: overlapping mechanisms and implications for metaplasticity. Neuropharmacology 52:156-175. CrossRef Medline

Tovar KR, Westbrook GL (1999) The incorporation of NMDA receptors with a distinct subunit composition at nascent hippocampal synapses in vitro. J Neurosci 19:4180-4188. Medline

Toyoda H, Zhao MG, Zhuo M (2005) Roles of NMDA receptor NR2A and NR2B subtypes for long-term depression in the anterior cingulate cortex. Eur J Neurosci 22:485-494. CrossRef Medline

Tracy TE, Yan JJ, Chen L (2011) Acute knockdown of AMPA receptors reveals a trans-synaptic signal for presynaptic maturation. EMBO J 30: 1577-1592. CrossRef Medline

Turrigiano G (2012) Homeostatic synaptic plasticity: local and global mechanisms for stabilizing neuronal function. Cold Spring Harb Perspect Biol 4:a005736. CrossRef Medline

Turrigiano GG, Nelson SB (2004) Homeostatic plasticity in the developing nervous system. Nat Rev Neurosci 5:97-107. CrossRef Medline

Turrigiano GG, Leslie KR, Desai NS, Rutherford LC, Nelson SB (1998) Activity-dependent scaling of quantal amplitude in neocortical neurons. Nature 391:892-896. CrossRef Medline

Wang HL, Zhang Z, Hintze M, Chen L (2011) Decrease in calcium concentration triggers neuronal retinoic acid synthesis during homeostatic synaptic plasticity. J Neurosci 31:17764-17771. CrossRef Medline

Watt AJ, van Rossum MC, MacLeod KM, Nelson SB, Turrigiano GG (2000) Activity coregulates quantal AMPA and NMDA currents at neocortical synapses. Neuron 26:659-670. CrossRef Medline

Wu G, Malinow R, Cline HT (1996) Maturation of a central glutamatergic synapse. Science 274:972-976. CrossRef Medline

Yashiro K, Philpot BD (2008) Regulation of NMDA receptor subunit expression and its implications for LTD, LTP, and metaplasticity. Neuropharmacology 55:1081-1094. CrossRef Medline

Yu LM, Goda Y (2009) Dendritic signalling and homeostatic adaptation. Curr Opin Neurobiol 19:327-335. CrossRef Medline 